\title{
Evaluation of the impact of active signage on road user behaviour at pedestrian crossings
}

\author{
Piotr Szagała ${ }^{1, *}$, Andrzej Brzeziński ${ }^{1}$, Paweł Dąbkowski ${ }^{1}$, Piotr Olszewski ${ }^{1}$, and Pawet \\ Włodarek ${ }^{1}$ \\ ${ }^{1}$ Warsaw University of Technology, Faculty of Civil Engineering, ul. Lecha Kaczyńskiego 16, 00-637 \\ Warszawa, Poland
}

\begin{abstract}
The main objective of the study was to verify the effectiveness of the active pedestrian crossings equipped with flashing lights activated automatically by detected pedestrians. Eight unsignalised pedestrian crossings were video-recorded for 48 hours each, both before and after installation of the equipment. An additional survey was done a month after the installation on three of the crossings. A traffic Conflict Rate was calculated for each crossing, as the number of conflicts per hour divided by the product of hourly pedestrian and vehicle traffic volume. The ANOVA test was used to check the statistical significance of changes of the indicators. The average percentage of drivers yielding to pedestrians increased by $94.8 \%$ and the average waiting time decreased by $39.2 \%$. The Conflict Rate decreased at five out of eight sites. The average speeds of vehicles approaching the crossings decreased by $3.9 \mathrm{~km} / \mathrm{h}$. The "before-one month after" analysis mostly confirmed the positive results of the first analysis. Generally, at four out of eight crossings the effects were clearly positive, at two, relatively positive, and at the remaining two there was no clear positive effect. These sites were multilane streets which suggests that such sites should be either signalised or narrowed.
\end{abstract}

\section{Introduction}

Although in the last few years the number of fatalities at pedestrian crossings in Warsaw has been gradually decreasing (by $20 \%$ in 2017 year on year), the number of 14 deaths recorded in 2017 requires further actions focused on reducing it. One such action has recently been implemented by the Warsaw Municipal Road Administration (ZDM) - a programme for traffic safety improvement by introducing the so-called active pedestrian crossings, equipped with flashing lights activated automatically by detected pedestrians. The crossings were also painted in red and equipped with skid resistant surface on the approaches (Fig. 1) [1]. The main objective of the study was to verify the effectiveness of 8 out of 19 newly introduced active pedestrian crossings, by assessing the relative changes of pedestrian safety and comfort of crossing a road. The results of the study helped ZDM improve operation of the crossings and to select new locations for future installations.

\footnotetext{
* Corresponding author: p.szagala@ili.pw.edu.pl
} 
Several innovative solutions for improving safety at pedestrian crossings are available on the market and are being tested in various countries [2]. Among those solutions are active signage systems which involve flashing lights warning drivers about the crossing location and pedestrian presence help to increase pedestrian visibility and induce drivers to lower their speeds. Operation of these lights requires a reliable system of automatic pedestrian detection - although this poses several challenges, such detectors are now becoming available [3]. According to American [4,5] and Israeli [6] field studies, active signage systems are quite effective in decreasing vehicle approach speeds and improving drivers behaviour in terms of willingness to give way to pedestrians. The Polish experience in this matter is also fairly positive [7].

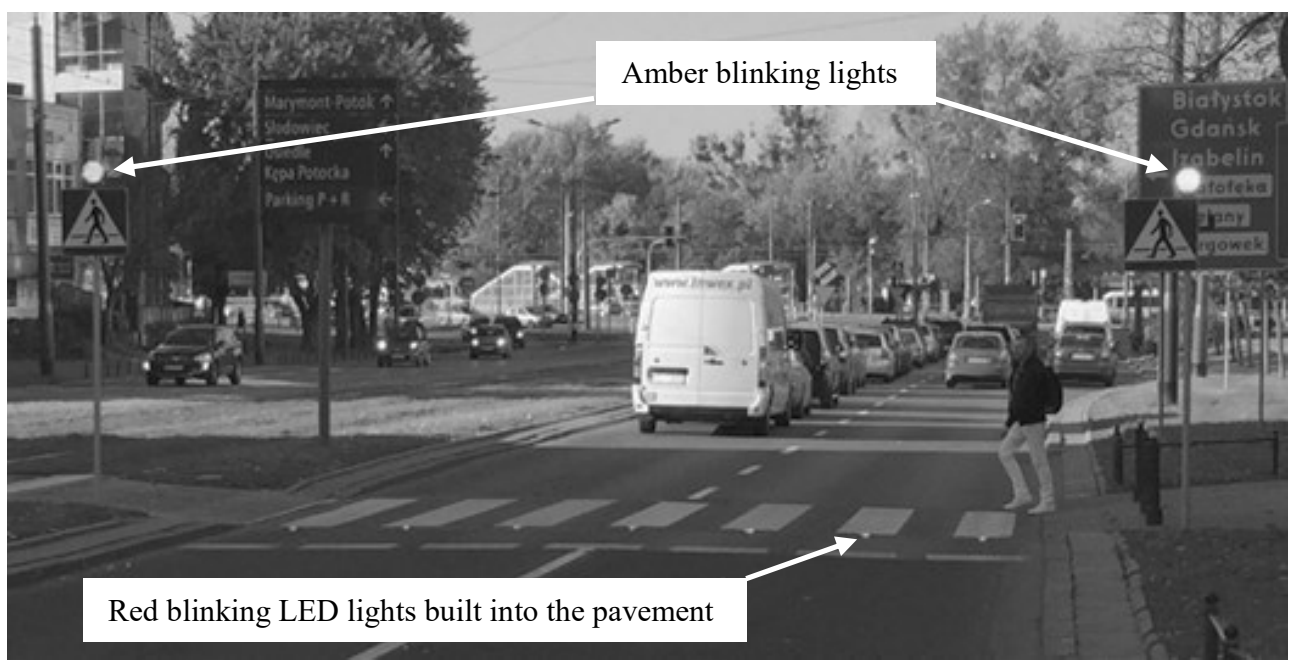

Fig. 1. Layout of the active pedestrian crossing (lights activated by pedestrians).

\section{Method}

A before-after analysis was conducted on eight selected unsignalised pedestrian crossings with different characteristics. The crossings were video-recorded using 2-3 MioVision Scout cameras per site for a period of 48 hours, both before and after installation of the equipment. The study was supplemented with an additional survey done a month after the installation on three of the crossings. The recordings were made in the period of JulyNovember 2017 and resulted in a total footage time of 900 hours. In total more than 23 thousand pedestrians and 35 thousand vehicles were registered. The following safety characteristics were analysed: pedestrian and vehicle traffic volume, the percentage of drivers yielding to pedestrians, the time lost by pedestrians waiting to cross and the average speeds of vehicles approaching the crossings (10 $\mathrm{m}$ before the crossing). Only drivers intentionally yielding to pedestrians were taken into account, so situations when pedestrians forced drivers to yield by stepping onto the crossing were not counted as yielding. The speed of vehicles was not taken into consideration for identifying yielding.

In order to exclude the impact of changes in traffic volume on vehicle speeds, a regression analysis of average hourly vehicle speed was performed as a function of the hourly vehicle traffic volume and the presence of the active signage. The percentage of drivers yielding to pedestrians was defined as a quotient of the number of drivers that yielded to pedestrians waiting to cross to the number of drivers that yielded and did not yield (among those which were in interaction). In contrast to other studies of this type [8], it 
was assumed that situations in which a pedestrian entering the crossing forced the vehicle to stop were not regarded as yielding. The time lost by pedestrians waiting to cross was defined as the average waiting time of all pedestrians at a particular site. Zero waiting times were not included in calculations.

A method of observing traffic conflicts was used to analyse the interactions between pedestrians and drivers, and to identify dangerous situations. General definition of a traffic conflict was given in 1977 as: "situation which would have led to an accident if none of the road users involved had taken any evasive action" [9]. Trained observers identified conflict situations using this definition, which was obviously somewhat subjective. A traffic Conflict Rate, as defined in [10], was calculated as the number of conflicts per hour divided by the product of hourly pedestrian crossing volume and vehicle traffic volume:

$$
\overline{C R}=\frac{10^{3} \sum_{i=1}^{n} C_{i}}{\sum_{i=1}^{n}\left(Q_{v i} Q_{p i}\right)}
$$

where:

$C R$ - average conflict rate;

$C_{i}$ - number of conflicts during hour $i$;

$Q_{v i}$ - motor vehicle volume during hour $i$;

$Q_{p i}$ - pedestrian volume during hour $i$ (group of pedestrians treated as one pedestrian);

$n$ - number of hours of observations.

In addition, the ANOVA test was used to check the statistical significance of changes of the indicators as a result of the introduction of the active signage.

\section{Results}

For each site groups of pedestrians were identified and based on that the number of pedestrians/groups entering the crossing was calculated (Fig. 2). Percentage of pedestrians in groups varied from $13 \%$ to $25 \%$ at different sites.

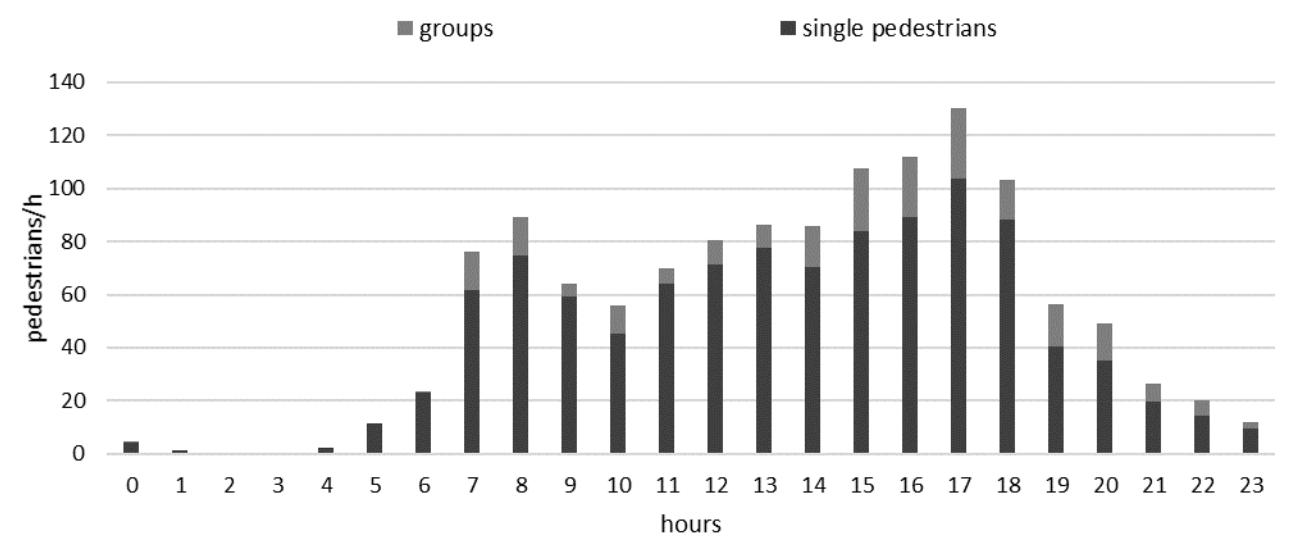

Fig. 2. Number of pedestrians/groups entering the crossing.

\subsection{Before-Immediately After Analysis}

The main characteristics of the analysed sites are shown in Table 1. 
Table 1. Main characteristics of the analysed sites.

\begin{tabular}{|c|c|c|c|c|c|}
\hline \multirow{2}{*}{ Site } & \multirow{2}{*}{$\begin{array}{l}\text { Cross- } \\
\text { section* }\end{array}$} & \multirow{2}{*}{$\begin{array}{c}\text { Maximum } \\
\text { vehicle traffic } \\
\text { volume } \\
\text { [veh/h] }\end{array}$} & \multirow{2}{*}{$\begin{array}{c}\text { Maximum } \\
\text { pedestrian } \\
\text { traffic volume } \\
{[\text { ped/h] }}\end{array}$} & \multicolumn{2}{|c|}{$\begin{array}{c}\text { Traffic } \\
\text { product** ('000) }\end{array}$} \\
\hline & & & & before & after \\
\hline Popiełuszki & $2 \times 2$ & 1006 & 124 & 116 & 121 \\
\hline Ludna & $1 \times 3$ & 679 & 155 & 81 & 120 \\
\hline Mickiewicza & $1 \times 4$ & 1454 & 80 & 65 & 115 \\
\hline Modlińska & $2 \times 3$ & 2761 & 23 & 78 & 99 \\
\hline Grzybowska & $2 \times 2$ & 604 & 443 & 202 & 267 \\
\hline Powstańców Śl. & $1 \times 4$ & 1266 & 93 & 57 & 131 \\
\hline KEN & $2 \times 2$ & 469 & 153 & 62 & 65 \\
\hline Waszyngtona & $1 \times 4$ & 1868 & 48 & 70 & 104 \\
\hline & Average: & 1263 & 140 & 90 & 141 \\
\hline
\end{tabular}

*For dual carriageway sites only one direction was analysed **Maximum product of pedestrian and vehicle hourly traffic volume

The resulting changes in the percent yielding and the Conflict Rate are shown in Fig. 3.

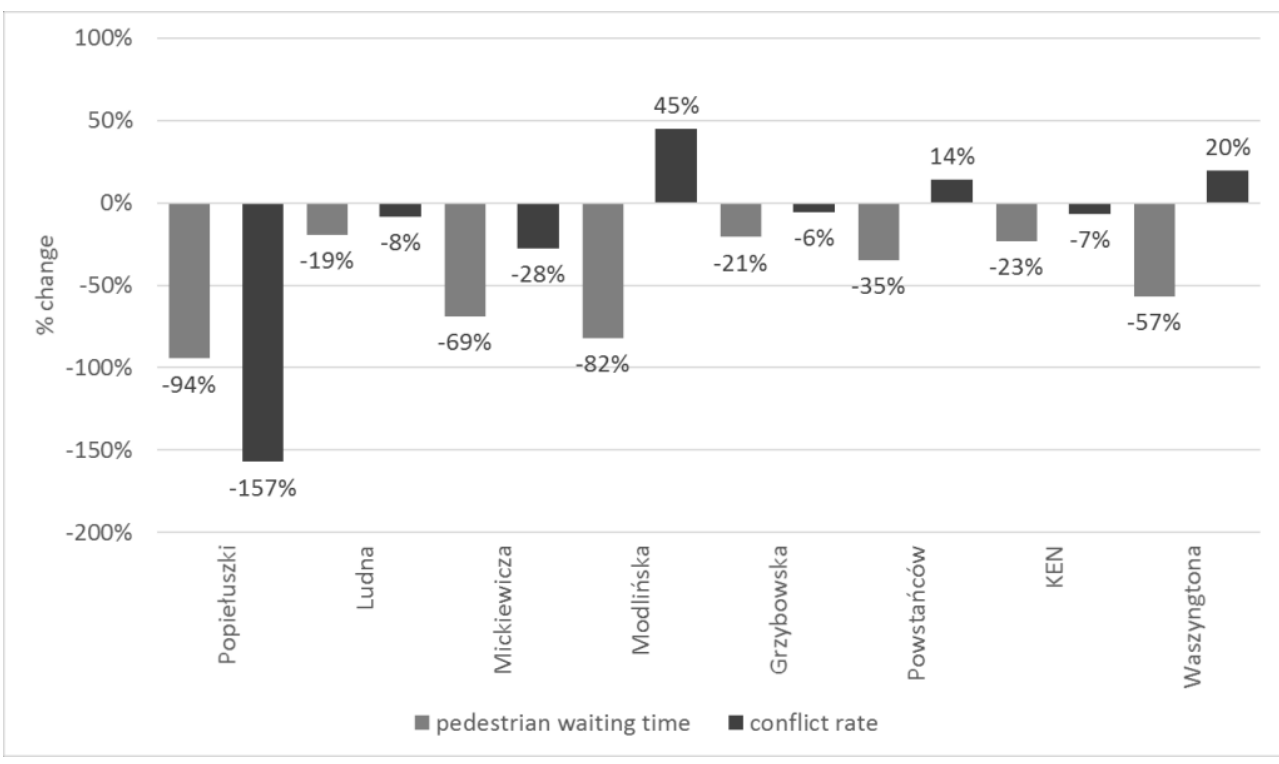

Fig. 3. Percentage change of pedestrian waiting time and Conflict Rate as a result of introducing the active signage.

Detailed information on yielding to pedestrians is included in Table 2.

After the installation of the active signage on all tested sites, the yielding percentage significantly increased. The largest increase (more than 10 times) was recorded at the Modlińska site, but the yielding percentage was very small, both before and after installation of the equipment. A similar phenomenon took place in the case of the Mickiewicza and Waszyngtona sites. According to the ANOVA test, in the case of the Powstańców Śl. and KEN sites, the recorded improvement cannot be considered statistically significant due to the large dispersion of results. 
Table 2. ANOVA test results of the statistical significance of change in the percentage of drivers yielding to pedestrians.

\begin{tabular}{|c|c|c|c|c|c|c|}
\hline \multirow{2}{*}{ Site } & \multicolumn{2}{|c|}{ Yielding } & \multirow{2}{*}{$\begin{array}{c}\text { Difference } \\
\text { (p.p.) }\end{array}$} & \multirow{2}{*}{ Change, $\%$} & \multicolumn{2}{|c|}{ ANOVA test results } \\
\cline { 2 - 3 } & Before & After & & $\mathrm{F}$ & $\mathrm{P}$ \\
\hline Popiełuszki & $23.2 \%$ & $46.5 \%$ & 23.31 & $100.4 \%$ & 35.46 & $0.000 *$ \\
\hline Ludna & $32.4 \%$ & $53.5 \%$ & 21.12 & $65.1 \%$ & 10.50 & $0.002 *$ \\
\hline Mickiewicza & $4.5 \%$ & $23.1 \%$ & 18.59 & $413.3 \%$ & 36.60 & $0.000 *$ \\
\hline Modlińska & $1.7 \%$ & $18.9 \%$ & 17.20 & $1011.8 \%$ & 19.23 & $0.000 *$ \\
\hline Grzybowska & $31.0 \%$ & $58.6 \%$ & 27.59 & $89.0 \%$ & 11.90 & $0.001 *$ \\
\hline Powstańców Śl. & $14.7 \%$ & $29.0 \%$ & 14.29 & $97.3 \%$ & 0.00 & 0.984 \\
\hline KEN & $42.6 \%$ & $56.5 \%$ & 13.91 & $32.6 \%$ & 0.86 & 0.357 \\
\hline Waszyngtona & $2.9 \%$ & $11.5 \%$ & 8.61 & $296.6 \%$ & 11.33 & $0.001 *$ \\
\hline Average: & $19.1 \%$ & $37.2 \%$ & $18.1 \%$ & $94.8 \%$ & - & - \\
\hline
\end{tabular}

$\mathrm{F}-$ Fisher's test used to assess confidence level $\mathrm{p}(*$ confidence $\mathrm{p} \leq 0,05)$.

Table 3 shows the results of pedestrians' average waiting time.

Table 3. ANOVA test results of the statistical significance of change in the average waiting time of pedestrians.

\begin{tabular}{|c|c|c|c|c|c|c|}
\hline \multirow{2}{*}{ Site } & \multicolumn{2}{|c|}{ Average waiting time } & \multirow{2}{*}{$\begin{array}{c}\text { Difference } \\
\text { (p.p.) }\end{array}$} & \multirow{2}{*}{ Change, $\%$} & \multicolumn{2}{|c|}{ ANOVA test results } \\
\cline { 2 - 3 } \cline { 6 - 7 } & Before & After & & & $\mathrm{F}$ & $\mathrm{P}$ \\
\hline Popiełuszki & 2.72 & 1.40 & -1.32 & $-48.5 \%$ & 15.835 & $0.000 *$ \\
\hline Ludna & 0.72 & 0.61 & -0.12 & $-15.3 \%$ & 0.066 & 0.799 \\
\hline Mickiewicza & 5.16 & 3.06 & -2.10 & $-40.7 \%$ & 12.373 & $0.001 *$ \\
\hline Modlińska & 12.54 & 6.88 & -5.65 & $-45.1 \%$ & 14.345 & $0.000 *$ \\
\hline Grzybowska & 0.53 & 0.44 & -0.09 & $-17.0 \%$ & 1.250 & 0.268 \\
\hline Powstańców Śl. & 3.12 & 2.32 & -0.80 & $-25.6 \%$ & 0.028 & 0.867 \\
\hline KEN & 0.71 & 0.58 & -0.13 & $-18.3 \%$ & 1.691 & 0.198 \\
\hline Waszyngtona & 7.27 & 4.64 & -2.63 & $-36.2 \%$ & 0.075 & $0.006 *$ \\
\hline Average: & 4.10 & 2.49 & -1.61 & $-39.2 \%$ & - & - \\
\hline
\end{tabular}

After installing the active signage the average waiting time to cross for pedestrians was significantly reduced on all the surveyed sites. This is directly related to the increase in the percentage of yielding - the drivers were more willing to give way to pedestrians. The average reduction in waiting time for all analysed sites was $39.2 \%$, which should be considered a very good result. The lowest reduction values were recorded at the crossings where the pedestrian waiting times were very short even before the active signage had been implemented. According to the ANOVA test, improvement at the Ludna, Grzybowska, Powstańców Śl. and KEN sites was not large enough to be considered statistically significant. The results on these sites are subject to high variability.

Less definitive results were obtained for traffic conflicts (Table 4) - the Conflict Rate decreased at five out of eight sites. The average speeds of vehicles approaching the crossings decreased by $3.9 \mathrm{~km} / \mathrm{h}$. The "before-one month after" analysis generally confirmed the positive results of the first analysis, mainly showing a further decrease of the traffic Conflict Rate. 
Table 4. The ANOVA test results of the statistical significance of change in the Conflict Rate.

\begin{tabular}{|c|c|c|c|c|c|c|}
\hline \multirow{2}{*}{ Site } & \multicolumn{2}{|c|}{ Conflict Rate } & \multirow{2}{*}{$\begin{array}{l}\text { Difference } \\
\text { (p.p.) }\end{array}$} & \multirow{2}{*}{ Change, $\%$} & \multicolumn{2}{|c|}{ ANOVA test results } \\
\hline & Before & After & & & $\mathrm{F}$ & $\mathrm{P}$ \\
\hline Popiełuszki & 0.55 & 0.22 & -0.34 & $-60.0 \%$ & 21.051 & $0.000 *$ \\
\hline Ludna & 0.46 & 0.42 & -0.04 & $-8.7 \%$ & 0.064 & 0.801 \\
\hline Mickiewicza & 0.83 & 0.65 & -0.18 & $-21.7 \%$ & 2.602 & 0.112 \\
\hline Modlińska & 0.06 & 0.10 & 0.05 & $66.7 \%$ & 4.887 & $0.031 *$ \\
\hline Grzybowska & 0.83 & 0.78 & -0.04 & $-6.0 \%$ & 0.001 & 0.970 \\
\hline Powstańców Śl. & 0.55 & 0.64 & 0.09 & $16.4 \%$ & 0.257 & 0.614 \\
\hline KEN & 0.74 & 0.70 & -0.05 & $-5.4 \%$ & 1.464 & 0.231 \\
\hline Waszyngtona & 0.28 & 0.35 & 0.07 & $25.0 \%$ & 4.013 & $0.050 *$ \\
\hline Average: & 0.54 & 0.48 & -0.06 & $-10.2 \%$ & - & - \\
\hline
\end{tabular}

The last analysed variable was vehicle speed $10 \mathrm{~m}$ before the crossing. Table 5 presents the results of the regression analysis of the average hourly speed of vehicles as a function of the hourly vehicle traffic and the presence of the active signage.

Table 5. The results of regression analysis of average hourly vehicle speeds.

\begin{tabular}{|c|c|c|c|c|}
\hline Site & $\begin{array}{c}\text { Speed difference before- } \\
\text { after }[\mathrm{km} / \mathrm{h}]\end{array}$ & $\begin{array}{c}\text { Standard error } \\
{[\mathrm{km} / \mathrm{h}]}\end{array}$ & $\begin{array}{c}\text { Confidence } \\
\text { level }\end{array}$ & $\mathrm{R}^{2}$ \\
\hline Popiełuszki & -2.95 & 0.46 & 0.000 & 0.65 \\
\hline Ludna & -3.88 & 0.61 & 0.000 & 0.70 \\
\hline Mickiewicza dir. 1 & -3.66 & 0.54 & 0.000 & 0.75 \\
\hline Mickiewicza dir. 2 & -5.31 & 0.95 & 0.000 & 0.53 \\
\hline Modlińska & -3.42 & 0.60 & 0.000 & 0.76 \\
\hline Grzybowska & -6.11 & 0.73 & 0.000 & 0.80 \\
\hline Powstańców Śl. & -5.96 & 0.44 & 0.000 & 0.88 \\
\hline KEN & 2.86 & 0.95 & 0.008 & 0.51 \\
\hline Waszyngtona dir. 1 & -5.29 & 0.86 & 0.003 & 0.50 \\
\hline Waszyngtona dir. 2 & -5.25 & 0.58 & 0.000 & 0.72 \\
\hline Average: & -3.90 & - & - & - \\
\hline
\end{tabular}

With the exception of the KEN site, the speed of vehicles at a distance of $10 \mathrm{~m}$ before the pedestrian crossing decreased at all the sites as a result of the active signage (the highest being on Grzybowska $-6.11 \mathrm{~km} / \mathrm{h}$ ). In all cases an appropriate level of significance and fairly good values of $\mathrm{R}^{2}$ were obtained. The lowest significance was obtained at the KEN site, where the range of "before" traffic volume was significantly lower than "after", thus it was difficult to obtain a good regression result. The increase in average speeds calculated in this case should therefore be treated with caution. The regression analysis is illustrated on Figure 4 (Powstańców Śl. site). 


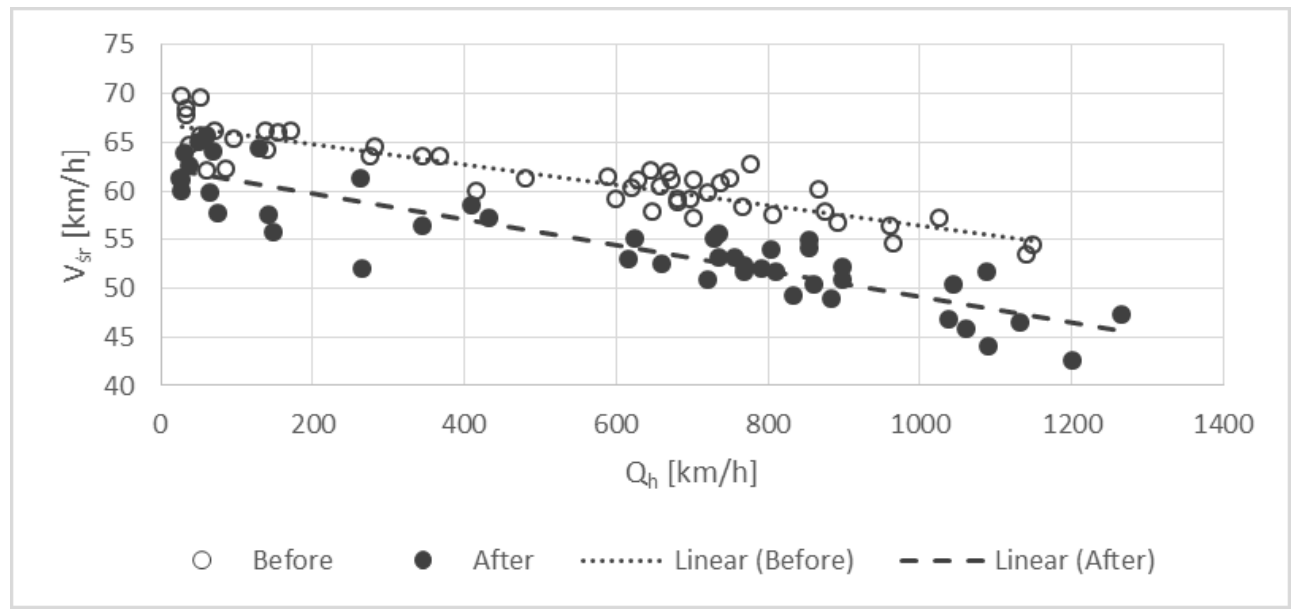

Fig. 4. The regression analysis of average vehicle speeds (Powstańców Śl. site).

\subsection{Before-One Month After Analysis}

In order to assess longer term effects, an additional survey was done approximately a month after the installation of the active signage at three of the analysed crossings. Summing up the results, it can be concluded that in two out of three cases the percentage of yielding has decreased - this is a negative effect, although the percentage of yielding was still significantly higher than in the "immediately before" study. In all cases, there was a further reduction in the pedestrian waiting time - which is a positive result. In all cases, there was a further decrease both in the numbers of conflicts and the values of the Conflict Rate - which is another positive effect.

There was a drop in the speed of vehicles at a distance of $10 \mathrm{~m}$ before the pedestrian crossing one month after installation of the active signage in comparison with the "before" situation at all analysed sites (on average $3.76 \mathrm{~km} / \mathrm{h}$ ). However, these decreases (except for the Ludna site) were slightly lower (at the Waszyngtona site even twice lower) than in the "immediately after" study. It can therefore be concluded that in the long term the speeds change differently depending on the location.

\section{Conclusion}

Several innovative solutions for improving safety at pedestrian crossings are available on the market and are being installed at selected locations. Active pedestrian crossing signs utilize flashing lights activated by pedestrian sensors to warn drivers of pedestrian presence. Before-and-after study of the effects of installing active signage systems at eight pedestrian crossings in Warsaw generally confirm positive results reported in international literature. After installing the system, percentage of drivers yielding to pedestrians increases and pedestrian delay decreases. What is more important from the safety point of view, the average approach speed of vehicles decreases.

The results are less clear with regard to the number of conflicts between pedestrians and vehicles. At several crossings the conflict rate decreased but there were also cases of where opposite result was observed. This may be caused by more assertive behaviour of pedestrians who feel more secure when the lights are flashing and are more inclined to step onto the crossing in front of approaching vehicles. 
In summarising the results, it can be stated that at four out of eight crossings the effects of introducing the active signage were clearly positive, at two, relatively positive, and at the remaining two installations did not bring a positive effect. These crossings were located on multilane streets which suggests that on such roads different safety treatments should be used. For example, such sites should be either signalised or the roads should be narrowed.

This article is based on a study carried out by the Warsaw University of Technology, Faculty of Civil Engineering, commissioned by the Warsaw Municipal Road Administration (ZDM).

\section{References}

1. Analysis of traffic safety on so-called Active Pedestrian Crossings (in Polish) (Warsaw Municipal Road Administration, 2017)

2. W. Czajewski, P. Dąbkowski, P. Olszewski, Innovative solutions for improving safety at pedestrian crossings, Arch. Transp. Syst. Telemat. 6 (2013)

3. F. Markowitz, J. Montufar, K. Lovejoy, Automated pedestrian detection: challenges and opportunities. Walk21 Paper (2012)

4. P.D. Prevedouros, Evaluation of in-pavement flashing lights on a six-lane arterial pedestrian crossing, in: ITE 2001 Annu. Meet., (ITE, 2001)

5. S. Turner, K. Fitzpatrick, M. Brewer, E. Park, Motorist Yielding to Pedestrians at Unsignalized Intersections: Findings from a National Study on Improving Pedestrian Safety, Transp. Res. Rec. J. Transp. Res. Board. 1982 pp. 1-12 (2006). doi:10.3141/1982-03

6. A.S. Hakkert, V. Gitelman, E. Ben-Shabat, An evaluation of crosswalk warning systems: effects on pedestrian and vehicle behaviour, Transp. Res. Part F Traffic Psychol. Behav. 5 pp. 275-292 (2002). doi:10.1016/S1369-8478(02)00033-5

7. P. Olszewski, W. Czajewski, P. Dąbkowski, C. Kraśkiewicz, P. Szagała, Assessment Of The Effectiveness Of Active Signage At Pedestrian Crossings, Arch. Civ. Eng. 61 pp. 125-140 (2015). doi:10.1515/ace-2015-0018

8. R.J. Schneider, A. Sanatizadeh, M.R.R. Shaon, Z. He, X. Qin, Exploratory Analysis of Driver Yielding at Low-Speed, Uncontrolled Crosswalks in Milwaukee, Wisconsin, Transp. Res. Rec. J. Transp. Res. Board. pp. 036119811878225 (2018). doi:10.1177/0361198118782251

9. F.H. Amundsen, C. Hydén, First Workshop on Traffic Conflicts (Institute of Transport Economics, Oslo/Lund Institute of Technology, Oslo, 1977)

10. P. Włodarek, P. Olszewski, Traffic safety on cycle tracks crossings - traffic conflict technique, in: Int. Cycl. Saf. Conf., (Bologna, 2016) 